\title{
A oralidade como conteúdo digital na graduação: uma experiência com o podcast em tempos de ensino remoto
}

DOI: http://dx.doi.org/10.21165/el.v50i2.3021

\author{
Hélio Rodrigues Júnior ${ }^{1}$ \\ Hélio da Guia Alves Junior²
}

\section{Resumo}

O presente artigo trata de uma experiência de ensino do gênero exposição oral envolvendo alunos do curso de Pedagogia durante o isolamento social provocado pela pandemia de Covid-19. Com o advento das novas tecnologias digitais de informação e comunicação, intermediando a interação didática de forma remota, surge a pergunta norteadora da pesquisa: no contexto do ensino remoto ocasionado pela pandemia, o podcast favorece 0 ensino do gênero exposição oral em um curso de formação inicial de professores? Desta forma, o objetivo geral é contribuir com a compreensão e o uso do gênero exposição oral no âmbito digital. Recorremos aos postulados sobre gêneros e oralidade de Antunes (2003), Bakhtin (2010), Bronckart (1985), Dolz et al. (2004), Fávero, Andrade e Aquino (2009), Marcuschi (2003, 2007, 2008), Schneuwly e Dolz (2004); às perspectivas das NTICs de Xavier e Marcuschi (2004).

Palavras-chave: ensino remoto; gênero exposição oral; ensino de gêneros orais; NTICs.

\footnotetext{
1 Faculdade de São Vicente (UNIBR), São Vicente, São Paulo, Brasil; h-rodrigues-junior@uol.com.br; https://orcid.org/0000-0002-5385-6393

2 Faculdade de São Vicente (UNIBR), São Vicente, São Paulo, Brasil; hdg.jr@hotmail.com; https://orcid.org/0000-0002-5643-8656
} 


\title{
Orality as digital content in graduation: an experience with podcasts in times of remote teaching
}

\begin{abstract}
This article deals with a teaching experience of the oral exposure genre involving students of the Pedagogy course during the social isolation caused by the Covid-19 pandemic. With the advent of new digital information and communication technologies mediating the didactic interaction remotely, the guiding question of the research arises: in the context of the remote teaching caused by the pandemic, the podcast favors the teaching of the oral exposure genre in an initial training course of teachers? Thus, the general objective is to contribute to the understanding and use of the oral exposure genre in the digital sphere. We used the postulates on genres and orality by Antunes (2003), Bakhtin (2010), Bronckart (1985), Dolz et al. (2004), Fávero, Andrade and Aquino (2009), Marcuschi (2003, 2007, 2008), Schneuwly and Dolz (2004); to the perspectives of the NTICs of Xavier and Marcuschi (2004).
\end{abstract}

Keywords: remote teaching; genre oral exposure; teaching oral genres; ICT.

\section{Introdução}

O presente estudo trata de uma abordagem qualitativa de natureza aplicada com objetivo exploratório do ensino e da aprendizagem da exposição oral como gênero textual por intermédio do recurso tecnológico podcast no curso de graduação em Licenciatura em Pedagogia, no âmbito da disciplina de Tecnologias da Informação e da Comunicação, ministrada para alunos do segundo semestre. Percebemos que, por conta do ensino remoto provocado pela pandemia do Covid-19, eles precisaram empregar meios alternativos para realizarem suas atividades didáticas. Entre os diversos recursos que as Novas Tecnologias da Informação e da Comunicação (NTICs) oferecem, selecionamos o podcast como recurso didático para promover a compreensão dos usos do gênero exposição oral.

Por consequência, motivamo-nos a olhar a referida plataforma como um suporte viável para o ensino de gêneros orais na graduação, avaliando até que ponto ele poderia constituir ganhos reais para a competência comunicativa em língua materna dos alunos no gênero em questão ou apenas ser uma alternativa pedagógica para a exposição oral.

A partir disso, tomamos como norteamento a seguinte pergunta: no contexto do ensino remoto ocasionado pela pandemia, o podcast favorece o ensino do gênero exposição oral em um curso de formação inicial de professores? Logo, nosso objetivo geral é contribuir com a compreensão e o uso do gênero exposição oral no âmbito digital. Os específicos são: (i) estudar o gênero exposição oral; (ii) relacionar o podcast com o ensino da oralidade 
por meio do gênero oral; (iii) analisar os limites e os alcances do podcast como recurso didático para a promoção da eficiência na comunicação oral do professor em formação inicial.

Para tanto, utilizamos os postulados sobre oralidade e gêneros de Antunes (2003), Bakhtin (2010), Bronckart (1985), Dolz et al. (2004), Fávero, Andrade e Aquino (2009), Marcuschi (2003, 2007, 2008), Schneuwly e Dolz (2004); e as perspectivas das NTICs de Marcuschi e Xavier (2004).

Como consequência, o corpus foi constituído por exposições orais apresentadas em formato de podcast pelos alunos da disciplina de Tecnologias da Informação e Comunicação no final do semestre do curso de licenciatura em Pedagogia. Essas práticas orais foram elaboradas com o objetivo de expor, de forma estruturada, um conceito diretamente ligado aos estudos das NTICs na Educação. Ao analisarmos 24 produções orais, verificamos o conteúdo temático, o estilo e a construção composicional das amostras com a finalidade de compreender os limites e alcances do podcast enquanto ferramenta de ensino da oralidade.

No momento de delimitação do escopo da pesquisa, notamos que ainda existia pouca informação disponível a respeito de experiências com sequências didáticas empregando o podcast como recurso pedagógico no ensino superior com o objetivo de tratar do ensino e da aprendizagem do gênero exposição oral com professores em formação durante o ensino remoto emergencial, situação que abriu a lacuna para a necessidade de seguirmos com o presente estudo.

\section{A oralidade, o ensino e o gênero exposição oral}

Assentamos nossos estudos sobre o gênero exposição oral a partir da concepção de linguagem como interação (GERALDI, 1984), uma vez que assumimos o texto como lugar de interação entre os sujeitos sociais.

Trata-se da concepção sociointeracionista em que a linguagem é entendida como prática humana que estabelece uma mediação entre o sujeito e o mundo, já que permite a cada um expor, compreender, refletir, criticar, debater, planejar, propor, resolver, agir onde vive. Assim, nesse cenário de interação, o homem organiza diferentes atividades textuais e discursivas e desenvolve formas comunicativas materializadas na constituição dos mais vários gêneros.

Os gêneros, "formas relativamente estáveis de enunciados, disponíveis na cultura, caracterizados por três elementos: conteúdo temático, estilo e construção composicional" (BAKHTIN, 2010 [1979], p. 274), são vistos como o construto linguístico por meio do 
qual se concretizam as inúmeras práticas sociais em que são observadas as diversas situações comunicativas.

Em particular, os gêneros orais são desvelados em atividades orais que são percorridas no contexto da sala de aula como uma das habilidades a desenvolver no escopo da formação da competência comunicativa de quem aprende uma língua, ainda que percebamos que o papel central do ensino se constitui muito na prática do ler e do escrever.

Importante salientar que os documentos oficiais - norteadores do ensino do português na Educação Básica - como os Parâmetros Curriculares Nacionais (PCN) e a Base Nacional Comum Curricular (BNCC), por outro lado, valorizam as práticas orais e reverberam que cabe à escola ensinar o aluno a utilizar a linguagem oral no planejamento e concretização de apresentações públicas, na realização de entrevistas, debates, seminários, apresentações teatrais etc. Estendemos esse ensino do oral também à sala de aula da universidade.

Defendemos que, além do ensinar a ler e a escrever, é preciso didatizar na sala de aula as práticas orais ensejando que o aluno desenvolva habilidades para a formação de uma competência comunicativa na realização de situações de interação com a fala.

Por outro lado, tão importante também nessa prática de linguagem em sala de aula é evidenciar a necessidade de o professor explorar a escuta dos gêneros orais, ultrapassando as atividades de mera oralização da leitura ou circunstâncias nas quais os alunos apenas usam a voz para o outro escutar. Nesta didatização do gênero, o mais importante acerca do ensinar a ouvir é evidenciar as características gerais da exposição oral, considerada, conforme os postulados de Dolz et al. (2004, p. 217) a respeito dos estudos de Bronckart (1985), "como um espaço-tempo onde o enunciador dirige-se ao destinatário, por meio de uma ação de linguagem que veicula um conteúdo referencial".

Isto posto, essas ações são necessárias para que o aluno perceba, ao escutar o gênero, o uso dele sob outros aspectos além da vocalização, visualizando sua circulação na sociedade, seus objetivos e os diversos elementos que interagem com ele no momento do uso, como o público, além daqueles que o compõem, como tema, estrutura composicional e estilo.

Vale destacar, ainda, que a sala de aula, quer da Educação Básica, quer do Ensino Superior, quando supera o abandono da oralidade nas atividades docentes, desvela situações de interação, contemplando a língua não apenas como um sistema que rege o bem falar, nem como um código que possui regras que, combinadas, são capazes de transmitir uma mensagem de um emissor a um receptor, mas também como uma atividade interativa que considera o plano enunciativo e dialógico. 
Afirma Marcuschi (2007) que, nas relações humanas do cotidiano, a fala, as práticas orais são mais recorridas do que a escrita por uma grande parte de pessoas. Na contramão, os projetos de ensino não dão a necessária importância para a oralidade. Trata-se, dessa forma, de uma mudança que deve ocorrer na postura pedagógica do professor.

O autor acrescenta que o ensino das práticas orais não recebe o devido tratamento, uma vez que é explorado pela leitura em voz alta, pela oralização do texto escrito. A preocupação fica circunscrita à pronúncia e à articulação das palavras. Notamos, consequentemente, que não há atividades planejadas para promover a interação e a adequação da fala às situações comunicativas orais (MARCUSCHI, 2007).

Por esse motivo, é imprescindível que o ensino da modalidade oral adentre às salas de aula, já que nossos alunos precisam passar pelas situações distintas de fala em seu processo formativo.

Chamamos a atenção para o fato de que os professores acabam ficando responsabilizados a rever seus projetos pedagógicos e os currículos dos cursos, colocando o aluno a vivenciar reais situações da modalidade oral, a ter contato com os mais diversos gêneros orais, com o contínuo entre a fala e a escrita, com a mudança da modalidade da escrita para a fala e da fala para a escrita, cujo objetivo é levar quem aprende uma língua a saber diferenciar uma modalidade da outra e aplicar cada uma nas relações entre os sujeitos em cada esfera social.

Situando as características tanto da modalidade escrita quanto da modalidade oral, ambas apresentam dialogicidade, planejam-se textual e discursivamente, ativam conhecimentos, organizam estratégias com vistas à formação de sentidos, promovem um lugar de interação entre os sujeitos situados no mundo. As relações entre e fala e escrita fundem-se, não são lineares, já que denotam um dinamismo fundado no continuum fala-escrita que se revela entre essas duas modalidades nas ações de linguagem (MARCUSCHI, 2008).

Fávero, Andrade e Aquino (2009), a respeito das relações entre a fala e a escrita, corroboram a perspectiva de Marcuschi ao afirmarem que as duas modalidades se situam em um continuum fala-escrita, indo de um plano mais informal a um mais formal. As autoras destacam que, para a compreensão da relação entre fala e escrita, devemos considerar as condições de produção, o contexto e a ação linguageira nas mais diversas situações de interação.

Além disso, as autoras defendem que a diferença entre a oralidade e a escrita se dá nas escolhas do enunciador, nas especificidades da situação de uso, na definição dos gêneros com o propósito de se ter sucesso na situação planejada. Sendo assim, é a 
atividade de linguagem que favorece a seleção e o planejamento das produções na interação (FÁVERO; ANDRADE; AQUINO, 2009).

Sob outro ângulo, Antunes (2003) acredita que se faz necessário destacar que, no que pese as modalidades oral e escrita da língua apresentarem suas especificidades, contrastes e diferenças essenciais não são encontradas em ambas, já que as duas são organizadas e usadas na realização verbal de situações comunicativas. Elas se constituem por meio de diferentes gêneros, isso, sim; mas essa pluralidade de materializações textuais não denota sentido em diferenciar a modalidade oral como espontânea, relaxada e sem planejamento e a escrita uniforme correta. Isso não faz sentido. Veremos que a exposição oral é exemplo de um gênero oral que requer uma organização antecipada, o cumprimento de etapas, o atendimento a objetivos prescritos, um plano no percalço do efeito do sentido.

Schneuwly e Dolz (2004) destacam, por sua vez, o fato de que a escrita não é a substituta do oral e vice-versa, ou seja, que uma modalidade é recorrida em detrimento da outra. Ao tratar dessas relações sob a perspectiva de teorias específicas da fala e da escrita (MARCUSCHI, 2008), reforçamos que há uma generalização nessa compreensão e na ideia de que a fala é mal estruturada e de que a escrita atende os fundamentos normativos da língua. Essa ideia leva-nos a ignorar as possibilidades de uso das duas modalidades nos mais diversos contextos de produção, desconsiderando o fato de que há tanto na oralidade quanto na escrita situações de uso mais ou menos formais.

Os autores, apesar de partirem do pressuposto de que há diversos tipos de oral, tanto espontâneos quanto mais formais, consideram importante diferenciar dois tipos que têm características muito distintas: (i) o oral espontâneo, cujas marcas são a fragmentação e a descontinuidade, embora percebamos vários aspectos de regularidade em sua produção; e (ii) a oralização da escrita, que parte de um texto base escrito e que acaba ficando limitado a ele. Entre esses dois "orais" extremos, situar-se-iam todos os outros orais (SCHNEUWLY; DOLZ, 2004).

Para o trabalho da exposição oral como um gênero do discurso mais formal, devemos tratá-la como objeto de ensino, pois não se costuma abordá-la didaticamente; não se percorre a construção da linguagem expositiva como atividade; não se planeja um conjunto de estratégias concretas de intervenção; não se define um agrupamento de procedimentos explícitos de avaliação (DOLZ; SCHNEUWLY; PIETRO, 2004).

A exposição oral, segundo Dolz, Schneuwly e Pietro (2004), éum instrumento para aprender conteúdos, sendo o primeiro nível de intervenção, pois explora diversificadamente e seleciona a informação em função do tema e da finalidade visada e elabora um esquema destinado à apresentação oral. Do ponto de vista comunicativo, permite construir e exercer o papel de autoridade sobre o conteúdo. Por outro lado, tem caráter bastante monologal e necessita, por parte do expositor, de um planejamento à sua dimensão comunicativa. 
Para Bronckart (1985), a exposição é um espaço-tempo de produção onde o enunciador dirige-se ao destinatário por meio de uma ação de linguagem que veicula um conteúdo referencial. Nesse plano, Dolz, Schneuwly e Pietro (2004) defendem que o expositor e auditório são separados pela assimetria de seus respectivos conhecimentos sobre o tema: o expositor é o "especialista" e o auditório apresenta-se como alguém que quer aprender.

Observamos que a exposição é um discurso que se realiza numa situação de comunicação bipolar - orador/expositor $X$ auditório. $O$ expositor tende a reduzir a assimetria inicial dos conhecimentos. Ao longo de sua ação de linguagem, ele leva em conta o destinatário, o auditório, o que imagina que ele já saiba, suas expectativas e seu interesse.

O gênero exposição oral se concretiza, comumente, em atividades de seminários em que aquele que fala se apropria de conceitos, de informações, de novas formas de interlocução e planeja sua apresentação oral como um sujeito enunciador que percorre fazer-se compreender no evento comunicativo.

Para a organização do gênero exposição oral, o professor apresenta um conteúdo temático a partir do currículo do curso, sugere a pesquisa bibliográfica e leitura sobre o tema, organiza as apresentações, compartilha suas expectativas, didatiza as características do gênero exposição oral e propõe uma interação ativa entre os alunos expositores, a fonte de pesquisa e os alunos ouvintes. Os enunciados que orientam o conteúdo temático de uma exposição oral cumprem com a função comunicativa do gênero que é expor, conceituar, explicar, refletir ideias num contexto formativo e informativo.

Uma das características do gênero oral que se destaca é o cruzamento da modalidade da fala com a modalidade da escrita na sua construção composicional: trata-se de um texto falado, porém planejado. No âmbito da fala, a exposição oral acaba não sendo linear e abarca aspectos como o tom de voz, os gestos, os movimentos de corpo, a entonação da voz, as expressões faciais, o riso, o nervosismo. No âmbito da escrita, a exposição oral se influencia pela preocupação com a contextualização e o desenvolvimento do tema, com a progressão das ideias, com os planos referenciais, com a conclusão do dizer (DOLZ; SCHNEUWLY; PIETRO, 2004). Por outras palavras, é possível afirmar que o gênero exposição oral é proveniente da produção oral monologal (entonação, ritmo, fluidez verbal) de um texto escrito que segue um planejamento. Nessa exposição, devemos levar em conta o imediatismo, a interação face a face, o improviso, a recolocação, a interrupção, a retomada e, também, o planejamento objetivo.

A construção interna composicional do gênero exposição oral, conforme nos apresentam Dolz, Schneuwly e Pietro (2004), segue o seguinte modelo didático: 
Quadro 1. Construção interna composicional do gênero exposição oral

\begin{tabular}{|c|l|}
\hline Etapa & \multicolumn{1}{|c|}{ Descrição } \\
\hline Fase de abertura & $\begin{array}{l}\text { O expositor toma contato com o auditório. É o momento em que o } \\
\text { expositor é instituído como tal. Fase ritualizada. }\end{array}$ \\
\hline $\begin{array}{c}\text { Fase de introdução } \\
\text { ao tema }\end{array}$ & $\begin{array}{l}\text { Momento da entrada no discurso. Trata-se da apresentação da } \\
\text { delimitação do assunto. }\end{array}$ \\
\hline $\begin{array}{c}\text { Apresentação do } \\
\text { plano da exposição }\end{array}$ & $\begin{array}{l}\text { Atividade metadiscursiva que torna transparente o planejamento da } \\
\text { exposição. }\end{array}$ \\
\hline $\begin{array}{c}\text { Desenvolvimento e o } \\
\text { encadeamento dos } \\
\text { diferentes temas }\end{array}$ & Fase que corresponde ao planejamento. \\
\hline $\begin{array}{c}\text { Fase de recapitulação } \\
\text { e síntese }\end{array}$ & $\begin{array}{l}\text { Retomada dos principais pontos da exposição como fase de } \\
\text { transição para o desfecho. }\end{array}$ \\
\hline Conclusão & $\begin{array}{l}\text { Apresentação das ideias finais, da transmissão de uma mensagem } \\
\text { de encerramento. Mas o expositor pode submeter aos ouvintes um } \\
\text { problema novo desencadeado pela exposição. }\end{array}$ \\
\hline Encerramento & $\begin{array}{l}\text { Última etapa compondo agradecimentos ao auditório. Fase } \\
\text { ritualizada. }\end{array}$ \\
\hline
\end{tabular}

Fonte: adaptado de Dolz, Schneuwly e Pietro (2004)

O estilo do gênero exposição oral é de caráter expositivo-argumentativo, altamente referencial e informacional, composto de operações linguísticas voltadas à apresentação das informações, das teses e dos argumentos estudados e construídos. Nesse processo, o expositor escolhe especificamente marcadores para a garantia da coesão temática, da articulação das diferentes partes sobre o que está sendo apresentado. Marcas textuais são usadas para a delimitação das partes da apresentação, a separação das ideias principais das secundárias, explicações com descrições, os argumentos, as reformulações, as sínteses. Esses aspectos marcam o estilo da exposição e desvelam o estilo pessoal do expositor no tratamento que dá ao tema (DOLZ; SCHNEUWLY; PIETRO, 2004).

Revelamos, assim, a didatização do ensino do gênero exposição oral seguindo os estudos da Escola de Genebra, com o objetivo de elucidar o subsídio teórico do qual o presente estudo decorre. 


\section{0 podcast como recurso didático para o ensino do gênero exposição oral}

Com o avanço das Novas Tecnologias de Informação e Comunicação, muitos obstáculos foram superados, permitindo que uma mensagem chegue a qualquer lugar do planeta em menos de um segundo. Essas transformações provocaram mudanças em todas as esferas de atividade humana, possibilitando novas arquiteturas do tempo e do espaço escolares, abrindo caminho para recursos digitais adentrarem a sala de aula, como no caso de ferramentas como o podcast.

O podcast é uma plataforma de transmissão on-line de áudios que pode ser acessada síncrona ou assincronamente por dispositivos eletrônicos móveis, como smartphones e tablets, ou por computadores pessoais, como desktops e laptops, com objetivos que percorrem a informação, o entretenimento, os estudos ou qualquer outra finalidade que possa se valer da escuta. Alguns streamers (pessoas que transmitem conteúdo pela internet) permitem o armazenamento local do arquivo de áudio, por meio de download, para ser escutado posteriormente de forma off-line. $O$ acesso ao conteúdo digital pode ser realizado por meio de aplicativos instalados nos dispositivos a partir de suas respectivas centrais de download, programas de computador disponibilizados para tal finalidade ou diretamente de sites, utilizando os navegadores (web browsers).

Influenciados pelos estudos de Marcuschi (2003), assumimos o podcast como um serviço que transporta os mais variados gêneros nas plataformas digitais, levando em consideração que ele possui características próprias, revestindo-se como um suporte tecnológico móvel que pode ser aproveitado no contexto de ensino, apresentando um grande potencial pedagógico por meio da manipulação de áudio.

Desta forma, por se tratar de uma mídia que pode ser adotada com facilidade mesmo por pessoas com pouca experiência digital, ela acaba favorecendo seu uso em contextos escolares para fins didáticos, principalmente em atividades que envolvam a oralidade. Portanto, considerando essa característica, empregamos o podcast no ensino de gêneros orais, delimitando-o como recurso principal em torno da engenharia da Sequência Didática para o ensino do gênero exposição oral. Além disso, a retextualização também está envolvida, já que os alunos primeiro preparam o roteiro de forma escrita para depois convertê-lo na performance oral do podcast.

Marcuschi (2008, p. 48), muito citado quando o assunto é reescrita, adotou o termo "retextualização para dar conta de uma atividade que envolve não apenas textos escritos, mas também orais" em uma mesma língua. Na concepção desse autor, o termo caracteriza a passagem não só de um texto escrito para outro texto escrito, mas também de um texto escrito para um texto oral e vice-versa. 
A visão teórica do autor fornece indicações para o trabalho de produção textual da perspectiva da retextualização, considerados os diferentes gêneros textuais, orais e escritos, como fontes de estímulo para a reflexão e ação sobre a linguagem. Em sua proposta, Marcuschi (2008) prevê que a passagem de uma modalidade para outra (fala/ escrita) pode ocorrer em diferentes níveis: 1. fala > escrita (entrevista oral > entrevista impressa); 2. fala > fala (conferência > tradução simultânea); 3. escrita > fala (texto escrito > exposição oral); 4. escrita > escrita (texto escrito > resumo escrito).

Nesse sentido, parece-nos pertinente inferir que a retextualização é uma modificação mais ampla do texto que, inclusive, pode alterar o meio em que ele é produzido/veiculado (entrevista oral na televisão para entrevista escrita no jornal impresso ou notícia impressa para notícia de rádio, por exemplo), o que confere ao trabalho com gêneros uma abordagem mais ampla e produtiva para os alunos. A reescrita, diferentemente, trata da passagem de texto escrito para outro texto escrito.

A respeito do ensino de gêneros orais no contexto escolar, Dolz, Schneuwly e Pietro (2004) sugerem a seguinte organização dos procedimentos didáticos para o ensino do gênero exposição oral:

Quadro 2. Sequência didática do gênero exposição oral

\begin{tabular}{|c|l|}
\hline Apresentação inicial & Compreender o contexto de produção de uma exposição oral. \\
\hline Oficina 1 & $\begin{array}{l}\text { Apreciar uma exposição oral e escutar atentamente para completar } \\
\text { um guia de escuta. }\end{array}$ \\
\hline Oficina 2 & Exercitar-se na utilização de anotações para a exposição oral. \\
\hline Oficina 3 & $\begin{array}{l}\text { Escolher um tema sobre a exposição, coletar referências e preparar } \\
\text { rotas para a exposição. }\end{array}$ \\
\hline Oficina 4 & Aprender a reformular palavras difíceis. \\
\hline Oficina 5 & Planejar o seminário/exposição e articular suas diferentes partes. \\
\hline Produção final & Tomar a palavra diante da classe. \\
\hline
\end{tabular}

Fonte: adaptado de Dolz, Schneuwly e Pietro (2004)

No esquema, observamos o percurso didático iniciando-se com uma apresentação do gênero, momento em que os alunos realizam sua produção inicial para que materializem o conhecimento e a compreensão que trazem sobre o gênero discutido. Em seguida, há o estabelecimento de uma grade, elaborado ao longo da atividade, para a seleção das informações. A partir da análise dessa primeira produção, oficinas são ministradas, funcionando como módulos de conceitos a serem trabalhados com o objetivo de fornecer 
aos alunos os saberes necessários para o uso adequado do gênero nas práticas sociais em que ele está inserido. São retomados todos os aspectos trabalhados ao longo da sequência e encaminhados à produção final, que é o momento em que os envolvidos aplicam o que foi aprendido ao longo da sequência didática, resultando em uma produção textual que se constitui a partir de um planejamento e de uma compreensão mais refinados das práticas e usos específicos do gênero trabalhado.

A partir desse modelo, a sequência didática foi adaptada para o uso com o podcast no contexto do ensino superior, respeitando os limites do ensino remoto, mas aproveitando os recursos trazidos à tona por ele que dificilmente poderiam ser experimentados em situações de normalidade pré-pandemia.

\section{Uma experiência com uma Sequência Didática planejada para o uso do podcast no ensino remoto}

A pesquisa se deu no segundo semestre de 2020, durante o ensino remoto emergencial provocado pela pandemia, razão pela qual toda a interação com os envolvidos se deu por mediação da ferramenta de videoconferência Google Meet, pelos recursos de compartilhamento do Google Drive e pelo ambiente virtual de aprendizagem Moodle. Os participantes são oriundos de uma faculdade privada localizada no litoral de São Paulo, envolvendo 40 alunos do curso de licenciatura em Pedagogia, no âmbito da disciplina de Tecnologias da Informação e da Comunicação. Os participantes foram organizados em oito grupos, compostos por cinco integrantes cada, para participarem da sequência didática projetada para o desenvolvimento de três podcasts por grupo, totalizando 24 produções, as quais constituíram o corpus do presente estudo.

Como procedimento metodológico, partimos de uma pesquisa bibliográfica (GIL, 2002) em torno dos estudos do ensino de gêneros orais e da sequência didática, aplicando-os a uma abordagem qualitativa por meio da pesquisa-ação (THIOLLENT, 1985), analisando os resultados da aplicação da Sequência Didática do gênero exposição oral proposta por Dolz et al. (2004), a qual foi adaptada para o uso do podcast e esquematizada da seguinte maneira: 
Quadro 3. Sequência didática aplicada

\begin{tabular}{|c|l|}
\hline Apresentação & Compreender o contexto de produção de um podcast. \\
\hline $\begin{array}{c}\text { Produção } \\
\text { inicial }\end{array}$ & Experienciar a Gravação de um podcast. \\
\hline Oficina 1 & $\begin{array}{l}\text { Apreciar um podcast educacional dialogado e escutá-lo atentamente para } \\
\text { completar um guia de escuta. }\end{array}$ \\
\hline Oficina 2 & Exercitar-se na utilização de anotações para o podcast. \\
\hline Oficina 3 & $\begin{array}{l}\text { Escolher um tema para o podcast, coletar referências e preparar rotas para } \\
\text { a exposição. }\end{array}$ \\
\hline Oficina 4 & Aprender a reformular palavras difíceis. \\
\hline Oficina 5 & Planejar o podcast e articular suas diferentes partes. \\
\hline Produção final & Gravar o podcast. \\
\hline
\end{tabular}

Fonte: Adaptado de Dolz, Schneuwly e Pietro (2004)

As produções orais oriundas dessa sequência didática foram elaboradas a partir da proposta aos alunos para que expusessem, de forma estruturada, assuntos diretamente relacionados às NTICs na educação. Os grupos escolheram os assuntos que gostariam de abordar, resultando nas produções orais das quais analisamos o conteúdo temático, o estilo e a construção composicional como conteúdo digital do gênero exposição oral adotados pelos participantes numa Sequência Didática planejada para o emprego do podcast.

\section{Resultados e análise do corpus}

Para analisar os resultados, selecionamos as categorias conteúdo temático, estilo e construção composicional dos podcasts produzidos, observando em que medida as produções finais, elaboradas depois da última oficina, haviam se tornado mais adequadas à estrutura da exposição oral em relação ao esboço que foi produzido antes da primeira oficina.

Na categoria de conteúdo temático, observamos se o conteúdo das produções estava dentro da proposta comunicativa especificada pelo professor. Na construção composicional, é possível ver de que forma os grupos estruturam sua produção oral, verificando a presença dos elementos que compõem o gênero exposição oral: tema, estrutura composicional e estilo. Neste último, a linguagem adotada pelo grupo foi observada em relação a sua proximidade com uma oralização da leitura ou com a espontaneidade e a capacidade didática que costumam ser encontradas nos podcasts informais dialogados destinados a alunos da educação básica. 
Desta forma, a fim de tornar os dados coletados mais claros, os quadros a seguir representam os resultados encontrados nas produções iniciais e finais dos grupos. A disposição dos itens no quadro revela a presença ou ausência dos elementos composicionais do gênero exposição oral e a adequação do estilo. Na sequência, encontra-se a síntese da análise dos resultados de 5 grupos escolhidos aleatoriamente entre os 8 que participaram da sequência didática.

Quadro 4. Análise das produções do grupo 1

\begin{tabular}{|c|c|c|c|}
\hline & & \\
\hline & & Produção inicial & Produção final \\
\hline \multirow{9}{*}{ 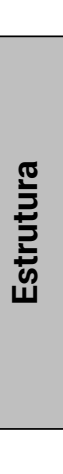 } & Tema & Cultura Maker & Hipermídia \\
\hline & Abertura & Presente & Presente \\
\hline & Introdução & Ausente & Presente \\
\hline & Apresentação do plano & Presente & Presente \\
\hline & Desenvolvimento do tema & Presente & Presente \\
\hline & Resumo/síntese & Ausente & Presente \\
\hline & Conclusão & Ausente & Presente \\
\hline & Encerramento & Ausente & Presente \\
\hline & Estilo & Oralização da leitura & Espontâneo \\
\hline
\end{tabular}

Fonte: Elaboração própria

No caso do primeiro grupo, cujo conteúdo temático foi a Cultura Maker, ao ouvir a amostra da produção inicial analisando o estilo da linguagem adotada pelos participantes, é possível perceber que, por conta do desconforto com o novo tipo de situação comunicativa, os expositores buscavam pela segurança oriunda da leitura do texto preparado para o podcast, resultando em um percurso narrativo muito mais focado em transmitir o conteúdo da exposição da forma mais rápida possível do que apresentá-lo de maneira dialogada, interativa e espontânea entre os expositores, fazendo com que a leitura oralizada do roteiro criado pelo grupo fosse interrompida abruptamente, sem preocupação com o encerramento da comunicação, já que não havia a compreensão de sua performance como algo que deveria ocorrer na relação com uma audiência. Portanto, essa ação linguageira representa a compreensão da gravação do podcast como um ato isolado, o qual não considera os possíveis ouvintes.

A produção final, cujo conteúdo temático foi a Hipermídia, a interação entre os expositores e os ouvintes ganha protagonismo no podcast, o turno de fala foi respeitado e a construção "Não é mesmo + [VOCATIVO]?" passou a ser utilizada nas interpelações e alternâncias de turno. Além disso, ao longo das oficinas, o grupo compreendeu a proposta e a construção composicional da exposição oral, resultando em uma apresentação cujos elementos do gênero estavam todos presentes e empregados de forma adequada à situação comunicativa. 
Ao compararmos os resultados coletados nas duas amostras fornecidas pelo primeiro grupo (produções inicial e final), é possível notar que todos os elementos esperados na estrutura composicional do gênero exposição oral estão presentes na produção final, revelando a internalização da função do gênero em questão pelos alunos, a qual resulta de uma prática de produção oral em ambiente digital constituída a partir de um planejamento que só se fez possível ao final da sequência didática, com a compreensão da função de cada uma das partes que compõem esse texto oral.

Quadro 5. Análise das produções do grupo 2

\begin{tabular}{|c|c|c|c|}
\hline & & Produção inicial & Produção final \\
\hline & Tema & PBL & Hipermídia \\
\hline \multirow{8}{*}{ 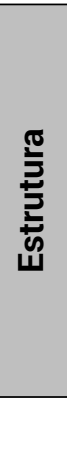 } & Abertura & Ausente & Ausente \\
\hline & Introdução & Presente & Presente \\
\hline & Apresentação do plano & Presente & Presente \\
\hline & Desenvolvimento do tema & Presente & Presente \\
\hline & Resumo/síntese & Ausente & Ausente \\
\hline & Conclusão & Ausente & Ausente \\
\hline & Encerramento & Ausente & Ausente \\
\hline & Estilo & Oralização da leitura & Oralização da leitura \\
\hline
\end{tabular}

Fonte: Elaboração própria

Na segunda amostra analisada, em ambas as produções do grupo, os envolvidos apresentaram problemas na compreensão da função do gênero na situação comunicativa em questão, por isso, não houve interação com os ouvintes, apresentação dos expositores, interpelação da audiência ou qualquer outro uso da função fática da linguagem. O planejamento não contemplou a apresentação dos falantes nem o encerramento adequado da transmissão, demonstrando que a preocupação dos alunos se concentrou quase exclusivamente no conteúdo da mensagem, ignorando a forma e o estilo. A espontaneidade não estava presente, já que os expositores permaneceram presos à leitura de seus registros durante toda a transmissão. 
Quadro 6. Análise das produções do grupo 3

\begin{tabular}{|c|c|c|c|}
\hline & & Produção inicial & Produção Final \\
\hline & Tema & PBL & Educomunicação \\
\hline \multirow{8}{*}{ 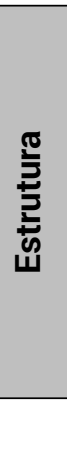 } & Abertura & Presente & Presente \\
\hline & Introdução & Ausente & Presente \\
\hline & Apresentação do plano & Presente & Presente \\
\hline & Desenvolvimento do tema & Presente & Presente \\
\hline & Resumo/síntese & Ausente & Presente \\
\hline & Conclusão & Ausente & Presente \\
\hline & Encerramento & Ausente & Presente \\
\hline & Estilo & Oralização da leitura & Oralização da leitura \\
\hline
\end{tabular}

Fonte: Elaboração própria

Desde a primeira produção, o grupo já compreendia a proposta comunicativa do podcast, o que resultou em maior interação e interpelação dos ouvintes. Na produção final, houve uma estruturação mais cuidadosa do percurso da fala e da caracterização do podcast, contando até mesmo com a vinheta durante a abertura da transmissão. Entretanto, os expositores ainda demonstraram marcas de oralização da leitura, o que os impediu de apresentar uma fala espontânea.

Quadro 7. Análise das produções do grupo 4

\begin{tabular}{|c|c|c|c|}
\hline & & Produção inicial & Produção final \\
\hline & Tema & Ensino Híbrido & $\mathrm{PBL}$ \\
\hline \multirow{8}{*}{ 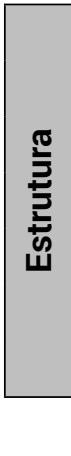 } & Abertura & Presente & Ausente \\
\hline & Introdução & Ausente & Presente \\
\hline & Apresentação do plano & Presente & Presente \\
\hline & Desenvolvimento do tema & Presente & Presente \\
\hline & Resumo/síntese & Ausente & Presente \\
\hline & Conclusão & Ausente & Presente \\
\hline & Encerramento & Presente & Ausente \\
\hline & Estilo & Oralização da leitura. & Oralização da leitura. \\
\hline
\end{tabular}

Fonte: Elaboração própria

O grupo teve o cuidado de selecionar as leituras prévias e tentar encadeá-las de forma sistemática, no entanto, considerando a exposição como um espaço-tempo de produção onde o enunciador dirige-se ao destinatário por meio de uma ação de linguagem que veicula um conteúdo referencial (BRONCKART, 1985), a performance constituída unicamente em torno do objetivo de transmitir conteúdos por meio da leitura de suas 
anotações não foi capaz de garantir uma articulação de ideias que possibilitasse a coerência necessária para a compreensão delas, resultando em um produto oral que, apesar da tentativa de estruturação e exposição da mensagem a partir de um roteiro, não considera a recapitulação de ideias, a abertura e o encerramento do circuito da comunicação, iniciando-o e concluindo-o de forma abrupta, negligenciando a audiência e sua adesão à fala e à tentativa de exposição de ideias.

Quadro 8. Análise das produções do grupo 5

\begin{tabular}{|c|c|c|c|}
\hline & & Produção inicial & Produção Final \\
\hline & Tema & $\begin{array}{l}\text { NTICs, ABP, Ensino híbrido e } \\
\text { Cultura Maker }\end{array}$ & $\begin{array}{c}\text { Cultura Maker, } \\
\text { multimodalidade, sala de aula } \\
\text { invertida e hipermídia }\end{array}$ \\
\hline \multirow{8}{*}{ } & Abertura & Presente & Presente \\
\hline & Introdução & Ausente & Ausente \\
\hline & Apresentação do plano & Ausente & Ausente \\
\hline & Desenvolvimento do tema & Presente & Presente. \\
\hline & Resumo/síntese & Ausente & Ausente \\
\hline & Conclusão & Ausente & Ausente \\
\hline & Encerramento & Ausente & Ausente \\
\hline & Estilo & Oralização da leitura & Oralização da leitura \\
\hline
\end{tabular}

Fonte: Elaboração própria

Em ambas as produções do grupo, cada um dos expositores, após uma curta vinheta, "recomeça" a exposição, como se fosse a primeira abertura de comunicação com a audiência. Além disso, a quantidade de temas (alguns repetidos) e a ausência de conexão entre eles dão a entender que não houve planejamento conjunto sobre a construção do podcast. Percebemos que cada aluno gravou o que foi do seu interesse, resultando em um amontoado de gravações desconexas, apressadas e que não estabelecem relação com nada fora do conteúdo delas mesmas. A compreensão do uso do gênero em uma situação comunicativa específica foi praticamente inexistente, já que estavam exclusivamente focados na leitura da maior quantidade possível de temas diferentes.

Após observarmos individualmente as produções dos grupos, olhamos para as 8 produções iniciais e as 8 produções finais, verificando as categorias de análise elencadas para considerar a ocorrência e o comportamento delas, buscando por constâncias nos usos adotados pelos alunos na situação comunicativa em questão.

Desta forma, quando nos voltamos para a categoria conteúdo temático, em sua totalidade, os grupos abordaram as Novas Tecnologias da Informação e Comunicação na Educação, conforme a proposta do professor para a situação comunicativa, fato que está 
relacionado à consciência de avaliação dos alunos, já que a abordagem de conteúdos não listados para a atividade não atenderia os requisitos do planejamento didático.

Quando consideramos a estrutura das produções dos grupos, podemos verificar a frequência com que os elementos composicionais do gênero exposição oral aparecem, percebendo que, em alguns deles, houve melhorias no emprego desses itens:

Quadro 9. Análise da Estrutura composicional

\begin{tabular}{|c|c|c|}
\cline { 2 - 3 } \multicolumn{1}{c|}{} & Produção inicial (\%) & Produção final (\%) \\
\hline Abertura & 87.5 & 75 \\
\hline Introdução & 50 & 87,5 \\
\hline Apresentação do plano & 75 & 75 \\
\hline Desenvolvimento do tema & 100 & 100 \\
\hline Resumo/síntese & 0 & 50 \\
\hline Conclusão & 0 & 50 \\
\hline Encerramento & 12,2 & 25 \\
\hline
\end{tabular}

Fonte: Elaboração própria

Constatamos quetodos os grupos construíram sua produção em torno do desenvolvimento do conteúdo, concedendo menor atenção aos itens da estrutura da exposição oral cujo maior foco está no interlocutor, quer a abertura, o resumo, a conclusão e o encerramento da comunicação. Essas atividades de linguagem que prestam o papel de contextualizar o ouvinte e ajudá-lo na recapitulação das ideias não foram mobilizadas na maior parte das produções iniciais. Os dados nos levam a crer que a compreensão da gravação como um ato isolado dos locutores ainda permanece sendo um dos principais problemas do entendimento do uso do gênero textual em questão, já que sua dimensão social e interativa não foi levada em consideração. Em outras palavras, a preocupação com a linguagem não ocupou o papel central no planejamento dos alunos, pois a maioria das escolhas não atendeu ao meio comunicativo que foi dado a eles, uma vez que se mantiveram restritos à preocupação com os conteúdos a serem transmitidos, desvelando o quanto essa estratégia de organização prejudica o alcance da função social do gênero exposição oral.

Sobre a categoria estilo, podemos considerar que ela foi o ponto mais crítico das produções, já que a passagem do escrito para o oral não foi realizada com eficiência, pois os grupos apenas oralizaram o texto escrito sem readequá-lo à nova situação comunicativa, sem compreendê-la como uma prática oral no ambiente digital, evidenciando que o registro escrito realizado pelos alunos com o objetivo de servir como suporte não considerou o contexto, a situação e o ambiente. Além disso, as escolhas lexicais, responsáveis pela impressão de pessoalidade, e as operações linguísticas específicas do gênero exposição oral adotadas pelos grupos não alcançaram os efeitos de estilo que trazem a 
espontaneidade, interatividade e dialogicidade esperadas na circunstância enunciativa. Essa questão abre espaço para a implementação de sequências didáticas que tragam um foco maior para adequação do estilo das produções orais.

Quadro 10. Análise da construção composicional

\begin{tabular}{|c|c|c|}
\cline { 2 - 3 } \multicolumn{1}{c|}{} & Produção inicial (\%) & Produção final (\%) \\
\hline Adequado & 0 & 12,5 \\
\hline Inadequado & 100 & 87,5 \\
\hline
\end{tabular}

Fonte: Elaboração própria

Com a leitura do quadro, podemos constatar que, nas produções iniciais dos grupos, todos adotaram um estilo inadequado para o podcast, realizando apenas a gravação de uma leitura em voz alta dos textos que preparam para o desenvolvimento do conteúdo. Apenas cerca de $12 \%$ das produções finais adotaram uma abordagem mais dialogada e espontânea.

Em suma, o conteúdo temático das apresentações, como pudemos ver nos exemplos, está ligado à proposta do professor, atendendo as características do gênero exposição oral.

O estilo permaneceu como principal problema, já que o rito de abertura, em que o expositor saúda a audiência e se define como um especialista que irá se dirigir a ela, não ocorre. Essa atividade, bastante ritualizada, não se concretizou, impedindo que se criasse a definição do momento de interação, das funções dos interlocutores e dos objetivos da exposição, limitando-se a uma leitura de um texto escrito, sem qualquer vínculo com os elementos externos. Dito de outra forma, a constituição do orador não se fez, pois não forneceu ao ouvinte as razões de suas preferências, a perspectiva adotada, as suas justificativas, prejudicando, inclusive, a mobilização da atenção, da vontade de aprender ou da curiosidade, ignorando a adesão da audiência.

No tocante à construção interna da exposição oral adotada pelos grupos, a instauração dos papéis de expositor e audiência, o tratamento, a introdução ao tema, a apresentação do plano da exposição e encadeamento das ideias seguiram a arquitetura do gênero. Na contramão, as fases de recapitulação, conclusão e encerramento não foram ritualizadas pela maioria dos envolvidos.

\section{Considerações finais}

Neste trabalho objetivamos compreender o uso do gênero exposição oral no âmbito digital da sala de aula remota e, dessa forma, pudemos contribuir com os limites e os alcances 
do podcast como recurso didático para a promoção da eficiência na comunicação oral do professor em formação.

Situada no cenário do ensino remoto que se colocou imperante nesses tempos da pandemia da Covid-19, vimos que a engenharia da sequência didática planejada em torno do podcast corrobora o quanto o gênero exposição oral é um objeto ensinável em sua situação comunicativa, em sua organização interna, em suas características linguísticas.

Apresentando a dimensão comunicativa do gênero exposição oral por meio de uma tecnologia - como a tomada de consciência da situação de comunicação de uma exposição, a estruturação de uma exposição, a hierarquização das ideias, o uso de reformulações, o desenvolvimento da competência metadiscursiva, a tomada de consciência do tom da voz, da fluidez verbal, da oralização do texto - recolocamos e valorizamos o ensino dos gêneros orais na academia.

Na sequência didática, os alunos demonstraram como principal dificuldade a compreensão das características gerais do gênero, bem como seu uso, fazendo com que ele fosse muitas vezes utilizado como mera retextualização de uma produção escrita no meio digital realizada de forma precária, ignorando as representações da situação de ação de linguagem planejada. Portanto, a partir da análise dos resultados, concluímos que os alunos demonstraram como principal dificuldade a compreensão das características gerais do gênero, bem como seu uso, fazendo com que ele fosse muitas vezes utilizado como mera retextualização de uma produção escrita no meio digital, sem levar em consideração as representações da situação de ação de linguagem planejada.

Assim, com esse tema, pensamos as práticas orais como objetos de ensino no contexto da sala de aula universitária que leva em conta o uso das NTICs, os gêneros como materializações das práticas sociais, a fala como uma dimensão humana a ser privilegiada na formação do sujeito, as características do gênero (conteúdo, estrutura, estilo, função sociocomunicativa e as condições de produção) como unidades de ensino.

\section{REFERÊNCIAS}

ANTUNES, I. Aula de português: encontro e interação. São Paulo: Parábola Editorial, 2003.

BAKHTIN, M. Estética da Criação Verbal. 5. ed. São Paulo: Martins Fontes, 2010.

BRONCKART, J.-P.; BAIN, D.; SCHNEUWLY, B.; DAVAUD, C.; PASQUER, A. Le fonctionnement des discours: um modèle psychologique et une méthode d'analyse. Paris: Delachaux et Niestlé, 1985. 
DOLZ, J.; SCHNEUWLY, B.; PIETRO, J-F. de; ZAHND, G. A exposição oral. In: SCHNEUWLY, B.; DOLZ, J. Gêneros orais e escritos na escola. Tradução Roxane Rojo. Campinas: Mercado de Letras, 2004.

FÁVERO, L. L.; ANDRADE, M. L. C. V. O.; AQUINO, Z. G. O. Oralidade e escrita: perspectivas para o ensino de língua materna. 7. ed. São Paulo: Cortez. 2009.

GERALDI, J. W. O texto na sala de aula. Cascavel: Assoeste, 1984.

GIL, A. C. Como elaborar projetos de pesquisa. 4. ed. São Paulo: Atlas, 2002.

MARCUSCHI, L. A. A questão do suporte dos gêneros textuais (parte 2). DLCV - Língua, Linguística \& Literatura, João Pessoa, v. 1 n. 1, p. 9-40, out. 2003. Disponível em: https:// periodicos.ufpb.br/ojs2/index.php/dclv/article/view/7435. Acesso em: 25 ago. 2020.

MARCUSCHI, L. A. Da fala para a escrita: atividades de retextualização. 9. ed. São Paulo: Cortez, 2008.

MARCUSCHI, L. A. Cognição, linguagem e práticas interacionais. Rio de Janeiro: Lucerna, 2007.

MARCUSCHI, L. A.; XAVIER, A. C. (org.). Hipertexto e gêneros digitais. Rio de Janeiro: Lucerna, 2004.

SCHNEUWLY, B.; DOLZ, J. Gêneros orais e escritos na escola. Tradução Roxane Rojo. Campinas: Mercado de Letras, 2004.

THIOLLENT, M. Metodologia da pesquisa-ação. São Paulo: Cortez, 1985. 